Department of Atmospheric Science, Colorado State University, Fort Collins, Colorado, U. S. A.

\title{
Moisture Analysis of an Extratropical Cyclone
}

\author{
J. L. Rasmussen, R. W. Furman, and H. Riehl
}

With 16 Figures

Received May 13, 1969

\section{Summary}

The atmospheric water balance and precipitation regime of a moving cyclone are described. The coordinate system chosen is one that moves with the traveling storm system. The computation of the atmospheric water balance is done to yicld the parameter precipitation minus evaporation as a residual. Good agreement is found between the water balance result and gauge data for three twelvehour periods. A technique, based on the conservation of equivalent potential temperature, to determine the flow of mass and moisture within the storm system is described. The results show that the cyclone studied changed in structure from a statically unstable to a stable system over 36 hours. The distribution of rate of condensation as a function of cloud temperature is determined and a distinct change in character of this parameter is noted as the storm structure is altered.

\section{Zusammenfassung}

\section{Feuchtigkeitsanalyse einer außertropischen Zyklone}

Der Wasserhaushalt und die Niederschlagsverhältnisse in einer wandernden Zyklone werden beschrieben, wobei ein Koordinatensystem benutzt wird, das mit dem Tiefdrudksystem mitwandert. Um den Parameter Niederschlag minus Verdunstung als Restglied bestimmen zu können, wird der Wasserhaushalt in der Atmosphäre berechnet. Es ergibt sich eine gute Übereinstimmung zwischen den Ergebnissen aus der atmosphärischen Wasserbilanz und den Daten der Niederschlagsmeßstellen für drei Perioden von je zwölf Stunden. Eine Methode, welche auf der Konstanz der äquivalentpotentiellen Temperatur beruht, gestattet es, Massenfluß und Feuchtestrom innerhalb der Zyklone zu beschreiben. Die Ergebnisse zeigen, daß die betrachtete Zyklone im Verlauf von 36 Stunden ihre statisch 
labile Struktur in ein stabiles System verwandelte. Es wird die Verteilung der Kondensationsrate als Funktion der Wolkentemperatur bestimmt und eine deutliche Änderung im Charakter dieses Parameters während der Umbildung der Struktur des Tiefdrudkgebietes festgestellt.

\section{Introduction}

\subsection{Background}

One recurring precipitation statistic that apparently is independent of geographical location is that roughly 50 percent of the annual precipitation over an area is due to the yield of 25 percent of the precipitation episodes $[2,8,9]$. Over the continental United States, these large precipitation events are reflections of the passage of synoptic scale cyclones. It is of interest, therefore, to investigate the precipitation mechanism of such disturbances and the role of the precipitation in the maintenance and dynamics of the system itself $[1,3,5]$.

Following the work reported by RIEHL and GraY [10], and keeping, to a large part, the objectives that they outlined, we wish to answer the following questions:

(a) What is the precipitation pattern with respect to the moving cyclone?

(b) Can the precipitation be computed with sufficient accuracy from the convergence of water vapor flux plus the change in storage of water vapor in the atmospheric volume encompassing the cyclone?

(c) Can inference be made with respect to the mass and moisture flow within the cyclone and, if so, what is the distribution of condensate as a function of temperature?

The solutions to these questions will require much serious effort. It is hoped that the program defined above will further our knowledge of the role played by smaller scale phenomenon, for example, the cumulus cloud system, in the cyclone dynamics. Further, it is hoped that the effect of weather modification on the structure and dynamics of the cyclone can be treated from analyses similar to the reseach described herein. This paper summarizes the detailed analysis of one storm for three computation periods during February 1961.

\subsection{Coordinate System and Method}

In order to isolate the synoptic scale cyclone from the larger scale circulation, we allow our coordinate system to move relative to the earth's surface. We fix the origin of the horizontal axes at the 
center of the surface low-pressure center with one axis lying along the direction of the storm heading (see Fig. 1). Because our purpose is to investigate the atmospheric water balance of the storm, we will choose an "area of interest" suitable in size to encompass the active

Fig. 1. Coordinate system used in the analysis. The arrow points in the direction of storm movement

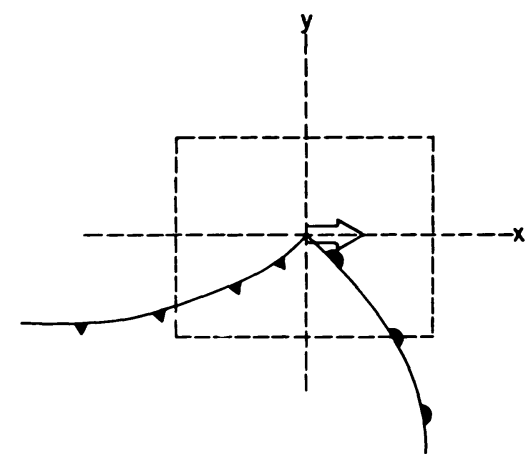

precipitation area of the storm, and not necessarily encompass the entire cyclone circulation system. The area of interest was chosen to be rectangular in shape, and symmetric around the above axes (Fig. 1). The volume of atmosphere existing above this area then will be studied in order to determine the atmospheric water balance of the precipitating area. It follows that the volume integral of the total derivative with respect to time of water mass is

$$
\begin{aligned}
\int \frac{d(q+r)}{d t} \varrho d V & =\int \frac{\partial(q+r)}{\partial t} \varrho d V+\int C_{n r}(q+r) \varrho \delta \sigma+ \\
& +\int \frac{\partial w(q+r)}{\partial z} \varrho \delta A \delta z .
\end{aligned}
$$

Here $q$ is specific humidity and $r$ is mass of water per mass of air. The integration is done over an atmospheric volume $V$ above an area of interest on the earth's surface; density is denoted by $\varrho, C_{n r}$ is the component of the wind relative to the moving coordinates and normal to an increment of area on the side of the volume, $\delta \sigma$, and defined positive outward; and $w$ is $\frac{d z}{d t}$. In the formulation of Eq. (1), the local change operator $\frac{\partial}{\partial t}$ is the local change following the moving coordinate system (see, for example [6], p. 48). 
Denoting the precipitation and evaporation rates as $P$ and $E$ respectively one obtains:

$$
P-E=-\frac{\partial}{\partial t} \int q \varrho \delta V-\int C_{n r} q \varrho \delta \sigma,
$$

where the contribution of the local change and horizontal flux divergence of liquid water and ice is assumed small $[4,7]$. Further, the volume is chosen sufficiently deep so that the flux of water and vapor at the top is negligible. Our object will be to evaluate the integrals on the right side of Eq. (2), thus determining $P-E$ as a residual. This technique will yield a value for $P-E$ distributed evenly over the storm area. For a more detailed discussion of technique, see [7].

We wish next to know the areal distribution of precipitation over the area of interest. The atmospheric water balance computation is done over the boundaries of the volume and does not yield any information on the distribution of precipitation within the storm area. Therefore, one must rely on the precipitation gauge data. Precipitation gauge data, however, are taken at permanent geographical locations, thus this data must be transformed to the moving coordinate system. Because a cyclone moves quite rapidly the daily precipitation data are an integration of the instantaneous precipitations falling over a long line element relative to the moving storm system (e. g. a line element of 1300 kilometers in length for a storm moving 15 meters per second) and thus daily data are not useful for a detailed instantaneous picture of the precipitation pattern with respect to the moving system. Hourly precipitation data, however, are of sufficient density and time resolution so that a pattern can be determined after a transformation to the moving coordinate system. Further, a check of the atmospheric water balance is possible through the use of this data if the evaporation rate is assumed negligibly small. This undoubtedly is true for a wintertime storm having heavy cloud cover and considerable precipitation.

Finally, one may infer a model of the vertical flow of mass and moisture within the volume by using thermodynamic constraints based upon the observed 12-hour data (normal wind component, temperature, pressure and moisture) along with the observed precipitation area and intensities. We propose to assume that the air conserves its equivalent potential temperature and therefore one may thermodynamically follow the air masses through the volume thus determining the distribution of condensation rate within the volume. From this information one may determine the distribution 


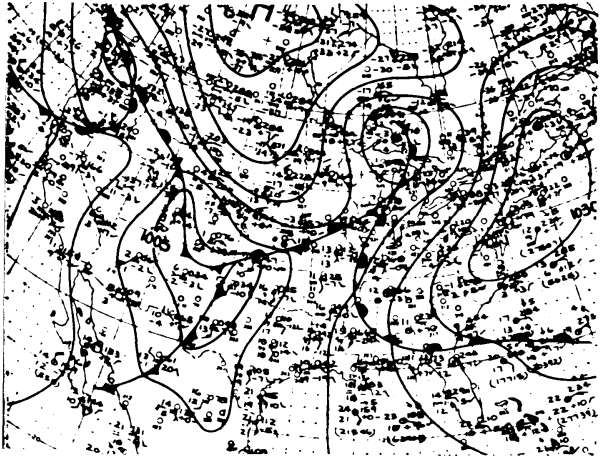

SURFACE

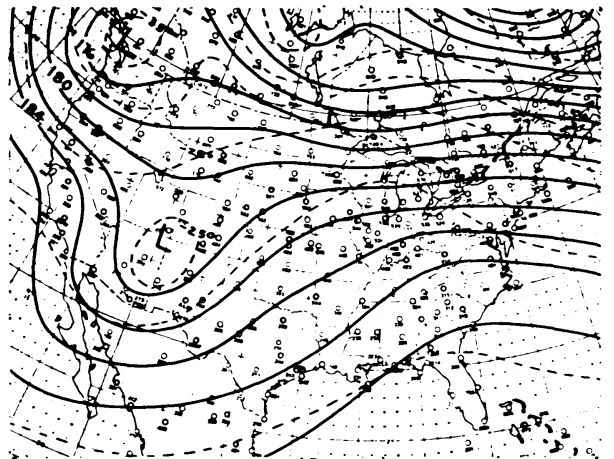

$500 \mathrm{MB}$

\section{FEBRUARY $19611200 Z$}

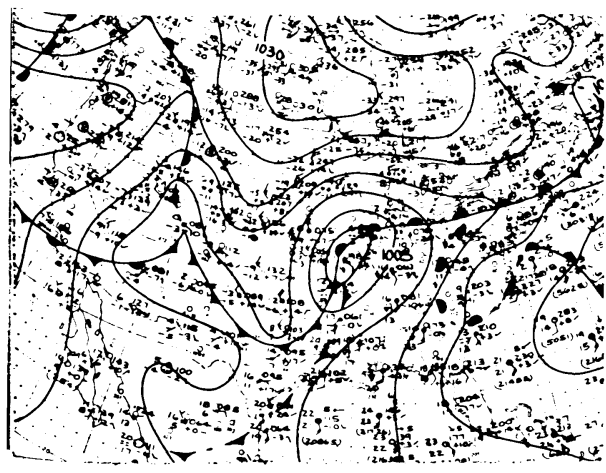

SURFACE

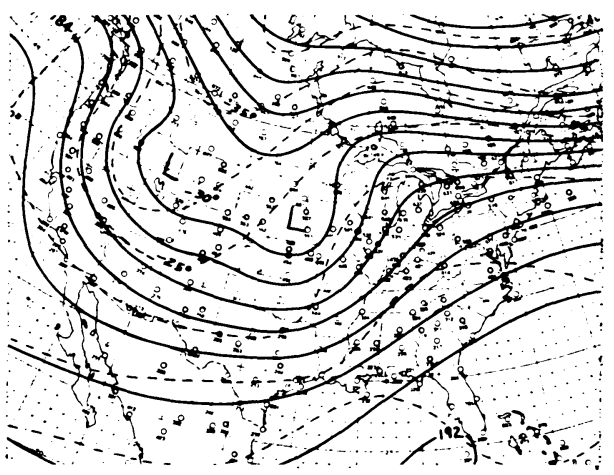

$500 \mathrm{MB}$

\section{FEBRUARY $19611200 Z$}

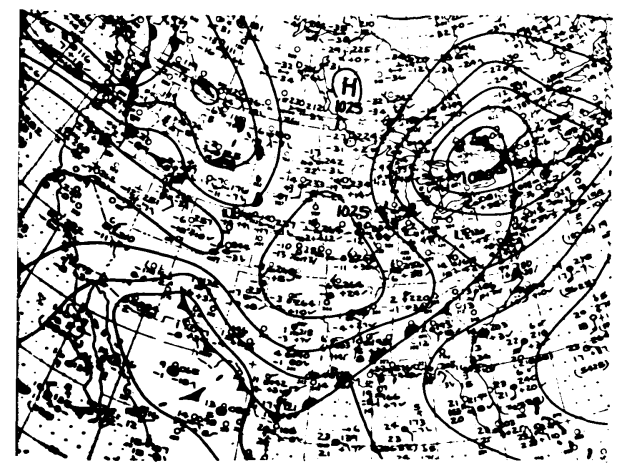

SURFACE

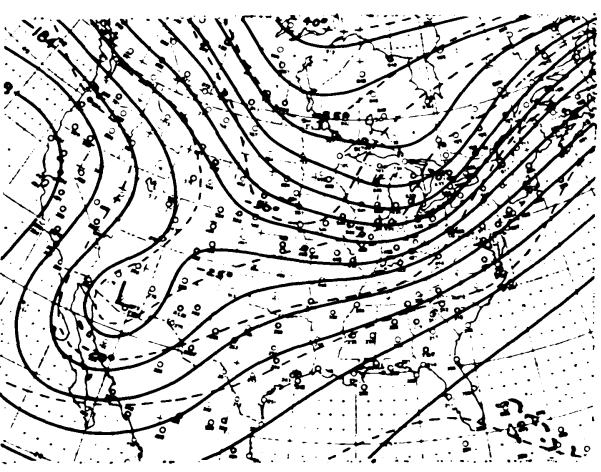

$500 \mathrm{MB}$

\section{FEBRUARY $19611200 Z$}

Fig. 2. Surface and $500 \mathrm{mb}$ maps showing the history of the storm system 
of rate of condensate formation with temperature, a necessary ingredient for an evaluation of the potential for cloud modification in such systems.

\subsection{Synoptic Picture of the Case to be Studied}

The cyclone described in this paper is an "average" wintertime system that had considerable but not excessive precipitation. The cyclone developed as a "Texas Panhandle Low" on the 1200 MGT, 17 February 1961 map (see Fig. 2) and proceeded in a general northeast heading crossing Lake Huron by 1200 MGT, 19 February. The circulation aloft remained an open wave with a cold dome at $500 \mathrm{mb}$ of the order of $-25^{\circ} \mathrm{C}$. The frontal system occluded between 1200 MGT, 18 February and 0000 MGT, 19 February. Considerable shower activity is noted on the surface data plotted on 1200 MGT, 18 February map.

\section{Method and Computation}

\subsection{The Atmospheric Water Balance}

The variables $C_{n r}$ and $q$ in Eq. (2) are not known continuously in space and time. The integrals in Eq. (2) therefore must be approximated using finite difference techniques suitable for the existing data. The data from the U.S. Weather Bureau radiosonde network was plotted at $50 \mathrm{mb}$ vertical intervals from the surface to $150 \mathrm{mb}$ and an analysis was performed to interpolate data to a 21 grid point network over the area of influence (Fig. 3). The data was tabulated

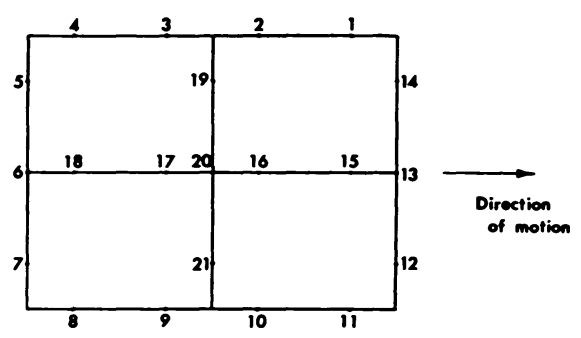

Fig. 3. The 21 point grid used in the analysis. The grid size is $6^{0} \times 8^{0}$ of latitude with $2^{0}$ of latitude between grid points

over this grid network at three observation periods; 18 February 1961,0000 and 12000 MGT; and 19 February 1961, 0000 MGT. The radiosonde station network and the three successive grid positions are shown in Fig. 4. The object of this analysis and grid point interpolation is to facilitate the evaluation of the integrals in Eq. (2). 
Let us define a boundary and area average of a quantity, for example, the specific humidity, $q$, as:

$$
\begin{aligned}
& \bar{q}_{j}=\frac{1}{l_{j}} \sum_{i=1}^{\mathrm{n}} q_{i j} \Delta l_{i} \\
& \hat{q}_{j}=\frac{1}{A_{j}} \sum_{k=1}^{\mathrm{m}} q_{k j} \Delta A_{k}
\end{aligned}
$$

(area average)

where $l_{j}=\sum_{i=1}^{\mathrm{n}} \Delta l_{i j}$ and $A_{j}=\sum_{i=1}^{\mathrm{m}} \Delta A_{k j}$, where $\Delta l_{i j}$ and $\Delta A_{k j}$ are increments of the boundary length and "horizontal" area on a pressure surface, respectively. The $j$ index denotes the pressure level,

Fig. 4. Track of the cyclone center and computation area. Circles denote radiosonde station locations used in the analysis

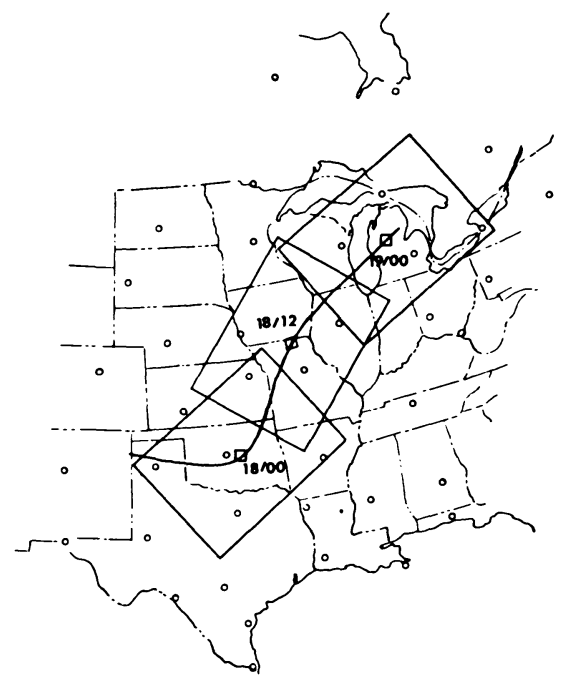

$i$ denotes a boundary grid point and $k$ denotes an area grid point. It follows then that $q_{i j}=\bar{q}_{j}+q_{i j}^{\prime}$ and $q_{k j}=\hat{q}_{j}+q_{k j}^{*}$ and that $\overline{q^{\prime}}{ }_{j}=\hat{q}_{j}{ }_{j}=0$. Eq. (2) may be rewritten in computational form as follows using pressure $p$ as the vertical coordinate:

$P-E=-\frac{\Delta}{\Delta t} \sum_{j=\mathrm{sfc}}^{\text {top }} A_{j} \hat{q}_{j} \frac{\Delta p_{j}}{g}-\sum_{j=\mathrm{sfc}}^{\text {top }} l_{j}\left(\bar{C}_{n r} \bar{q}\right)_{j} \frac{\Delta p_{j}}{g}-\sum_{j=\mathrm{sfc}}^{\text {top }} l_{j} \overline{\left(C^{\prime}{ }_{n r} q^{\prime}\right)_{j}} \frac{\Delta p_{j}}{g}$

where use has been made of the averaging notation (3). The radiosonde has a practical limit in the measure of water vapor. In the 
analysis of an extratropical winter storm of the nature discussed here it is only necessary to sum the $j$ index from the surface to $400 \mathrm{mb}$. Above this level, the instrument does not regularly measure the small quantity of water vapor and the omission of levels above this cannot greatly affect the computation. Thus, for purposes of the water balance the top of the volume will be considered $400 \mathrm{mb}$.

The layer nearest the surface was assumed to be represented by the $950 \mathrm{mb}$ data. This data was assigned the appropriate $\Delta p$ for the surface through $925 \mathrm{mb}$ at each grid point. The summation over the $j$ index then proceeds from $950 \mathrm{mb}$ to $400 \mathrm{mb}$ at $50 \mathrm{mb}$ intervals: this amounts to resolution of 12 levels in the vertical.

\subsubsection{Local Change Term}

The rate of change of the water vapor storage was computed for the observation times of $18 / 00,18 / 12,19 / 00$ MGT. The first term on the right of Eq. (4) estimates the local change in water vapor content in the volume moving with the storm. The change in water vapor storage was computed over a 24-hour period centered on the observation time. Fig. 5 shows the history of the

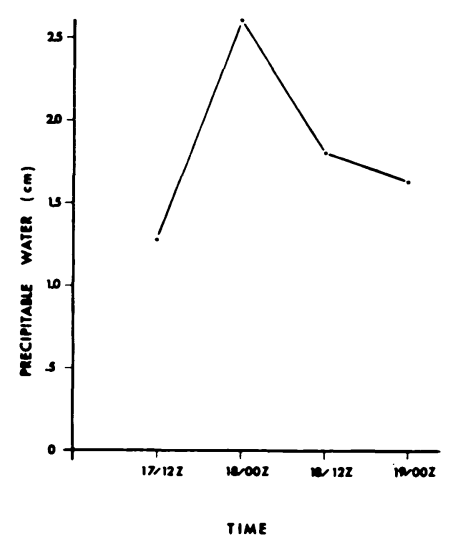

Fig. 5. The time section of precipitable water following the moving storm system

volume integrated vapor content of the storm. The change in storage was computed for 24-hour periods and this rate was assumed to be valid for a 12-hour period centered on the observation time. Care must be taken when applying non-centered local changes. Differences in the local change term of much as 100 percent could be obtained from the use of non-centered local change values for this case. 
Fig. 6 a gives the vertical distribution of the local change term for each of the three periods. Positive values of the term indicate that the atmospheric volume is increasing in water vapor content with time. Large changes are noted on the first period with the volume
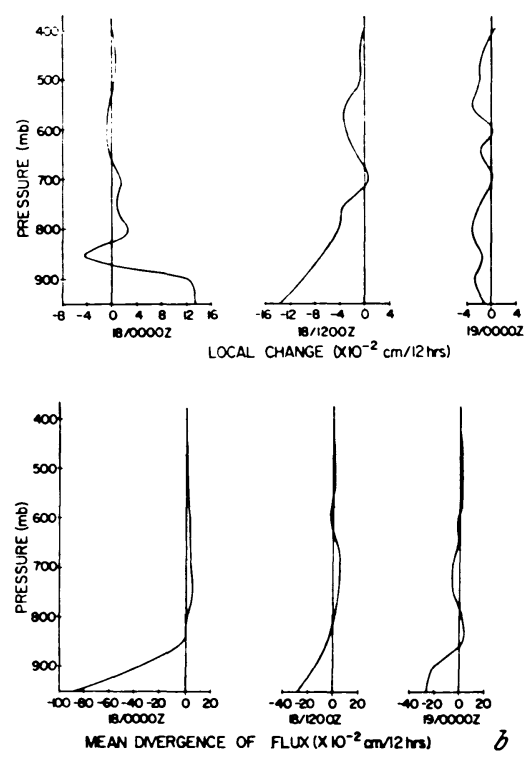

Fig. 6. Vertical profiles of terms in the water balance equation. (a) Local change in water vapor storage. (b) Divergence of water vapor flux due to mean wind. (c) Divergence of water vapor flux due to eddy wind

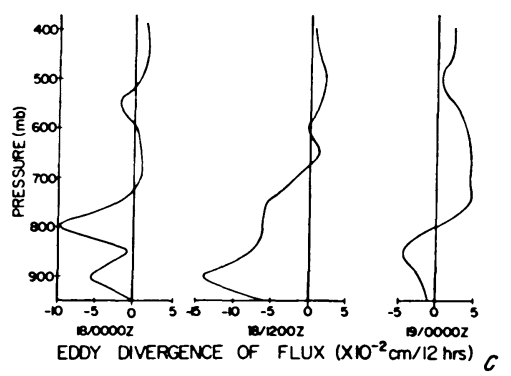

becoming wetter near the surface as the warm, moist, Gulf of Mexico air is intercepted. The opposite is the case on the second time period with the northward movement of the storm and the beginning of the occlusion process. The last period is typified by a near steady-state condition in water vapor content.

\subsubsection{Divergence of Moisture Flux Terms}

Fig. $6 \mathrm{~b}$ and $\mathrm{c}$ show the vertical distribution of the divergence of moisture flux due to the mean wind and the eddy motion, respectively. 
The vertical profiles of the mean or ageostrophic term show a dominant flux into the volume near the ground and a smaller outflow aloft. This is consistent with the expected ageostrophic wind distributions where there is frictional convergence near the ground and sub-geostrophic outflow aloft. A secondary layer of inflow aloft exists during the last time period.

The magnitude of the net eddy transport term (Fig. 6c) is small compared to the mean term but it is significant to note that particularly in the first two time periods, while the storm is developing and the surface pressure falling, wind and moisture fields are such that the air flowing into the storm from the surface up to $700 \mathrm{mb}$ is relatively moist, thus yielding a positive contribution to $P-E$. This effect largely is lost during the final time period due to the cutting off of the source of warm, moist, Gulf air. During this period the eddy term above $800 \mathrm{mb}$ exports water vapor from the volume.

\subsubsection{Summary}

Table 1 gives the results of the vertically summed terms of Eq. (t) and the residual, $P-E$, for each of the three time periods. The units for $P-E$ are given in a unit yield which, for example, on 18 February $0000 \mathrm{MGT}$, implies $1.0 \mathrm{~cm}$ uniformly covering the whole area of influence. The ageostrophic contribution dominates on the average but the other terms can be equally important, for example, on 18 February 1200 MGT much of the contribution to $P-E$ comes from the decrease in water vapor stored in the volume. Since in a developing cyclone such as this, one would expect strong mass convergence at the lower levels and divergence aloft, it is not surprising that the mean flux of moisture across the boundary is dominant [4].

Table 1. Results of the Water Balance Computation (cm/12 hrs)

\begin{tabular}{ccccc}
\hline $\begin{array}{c}\text { Date/Time } \\
\text { Feb. 1961 }\end{array}$ & Local Change & Mean Term & Eddy Term & $P-E$ \\
\hline 18/00 MGT & +.25 & +1.11 & +.15 & 1.0 \\
18/12 MGT & -.46 & +.34 & +.35 & 1.1 \\
19'00 MGT & -.18 & +.48 & -.17 & 0.5
\end{tabular}

Let us now assume that over the area of this storm the evaporation is small compared to the precipitation. This appears to be reasonable considering the temperature dewpoint spread at the surface and the cloud cover existing over the area (see Fig. 2). Under these con- 
ditions the computation then yields a value for precipitation alone. We propose to check this value against observed precipitation using hourly precipitation gauge data and further we propose to describe the distribution of precipitation as a function of space within the moving frame of reference.

\subsection{Direct Measurement of Storm Precipitation}

The U.S. Weather Bureau Hourly Precipitation Data were used to determine a separate precipitation estimate following the moving coordinate system. Fig. 7 shows the distribution of stations used in

Fig. 7. Storm track and hourly precipitation gauge locations used in the study

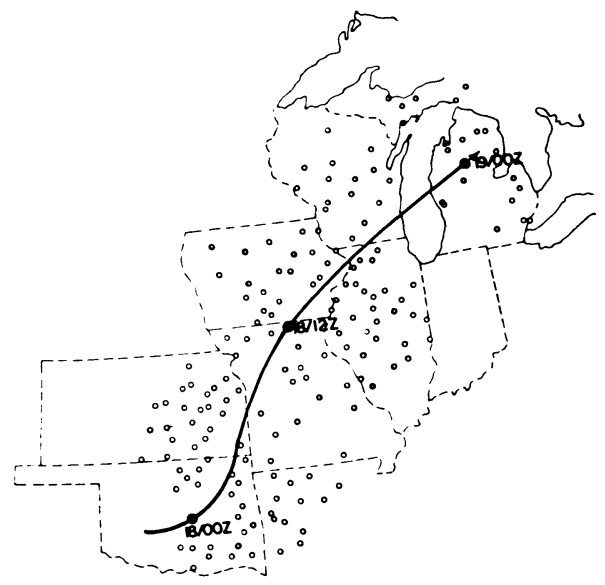

this compilation. The analysis technique was quite simple and straightforward. Fig. 8 shows a series of tracks of a few gauges as the storm moved relative to the gauges. The tracks are divided into the segments indicating hourly movement of the gauge and the corresponding hourly precipitation as plotted at the midpoint of the segment. The storm speed is such that the rain gauges traversed the area of interest in about 14 hours. The stations used to determine each of the respective 12-hourly precipitations were chosen so that they were located within four degrees of latitude of the center of the box at the rawinsonde observation times. After compiling all the hourly precipitation rates with respect to the storm center for each 12-hour period, the data were averaged over a grid of 80 equal area segments. From the field of area average quantities an analysis was performed yielding the hourly precipitation patterns shown in Figs. $9 \mathrm{a}, \mathrm{b}$ and c. One notes the dominant band of precipitation 
running diagonally across the box for early periods with a double maximum existing on both patterns. The banded pattern apparently moves with respect to the storm center progressing in the direction of storm movement and moving faster than the storm center. The precipitation intensity decreases with time. The last period is typified by an areal precipitation much less intense than the first periods and with-

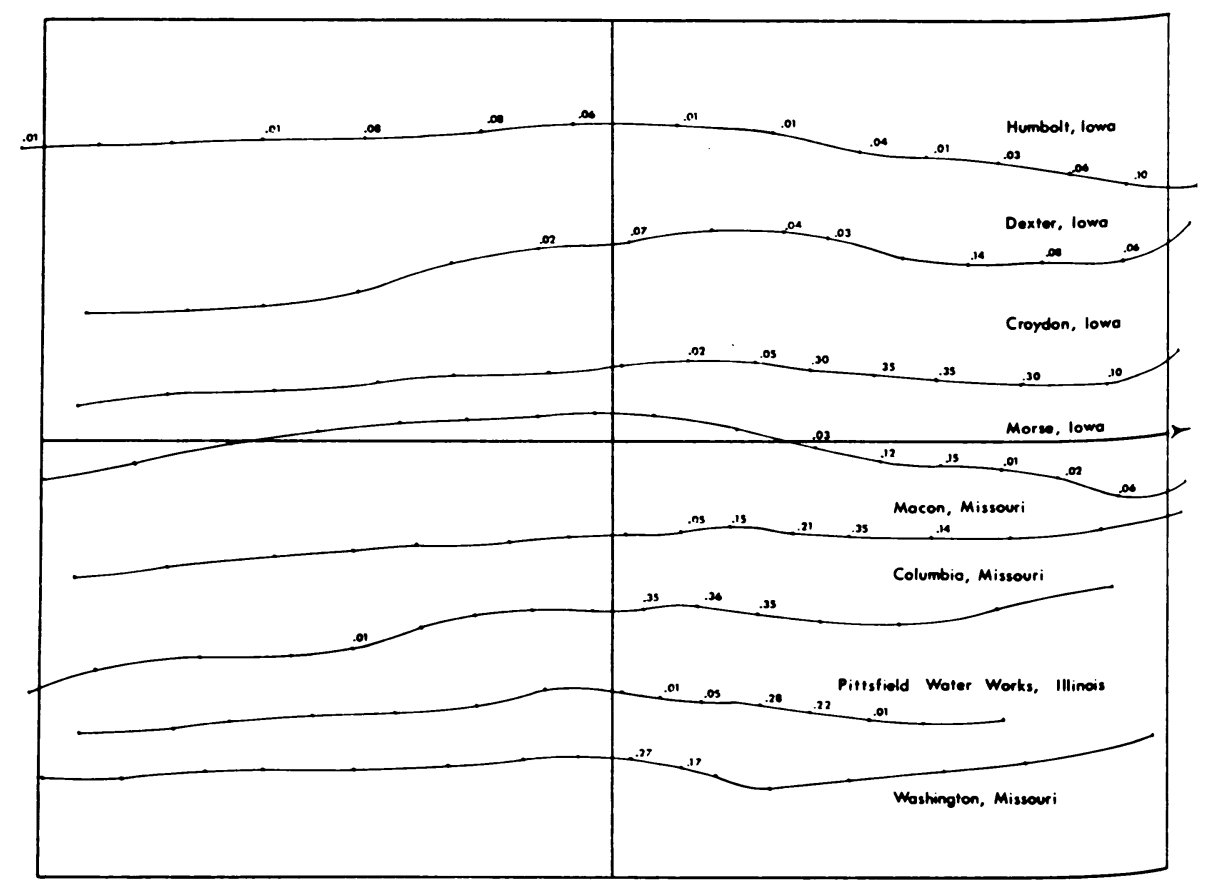

Fig. 8. Examples of the tracks of hourly gauges as they traversed the storm. Data is hourly precipitation (in/hour) plotted at the center of the corresponding hourly displacement of the gauge

out the banded feature. The important point to be derived from this analysis is that a very narrow and intense band of precipitation, hence vertical motion, is apparent within the larger cyclone system for the first two time periods. One may infer from this that early in the storm the ascending air is apparently localized over approximately 10 percent of the total area of influence and that one may picture the system as a "tower phenomenon". The last period does not exhibit this feature in the precipitation pattern within the area of interest. 
2.3. Comparison of Gauge Precipitation and Water Balance

Computing an area average yield from the distribution shown in Fig. 9 a through $9 \mathrm{c}$, one obtains the areal precipitation following

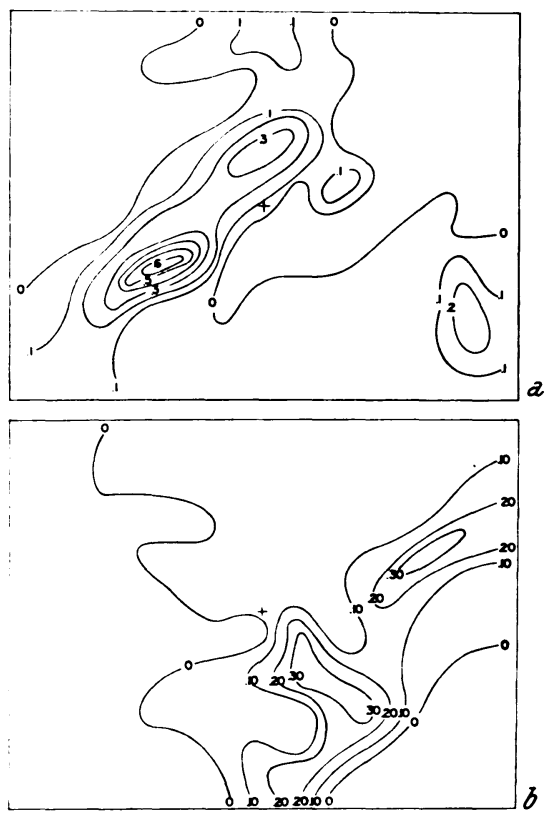

Fig. 9. Hourly precipitation rate for (a) $18 / 0000 \mathrm{MGT}$, (b) $18 / 1200 \mathrm{MGT}$, (c) $19 / 0000 \mathrm{MGT}(\mathrm{cm} / 12 \mathrm{hrs})$

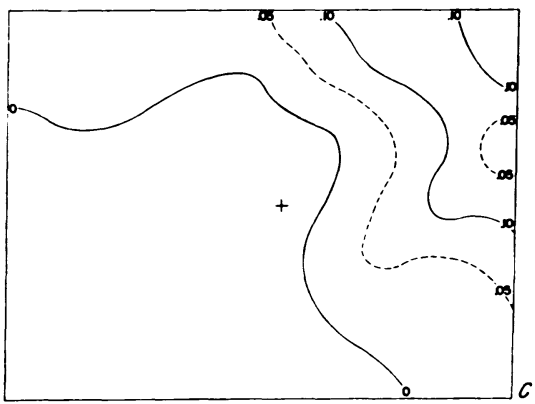

the storm as shown in Table 2. These values for the 12-hourly precipitation are within 10 percent of that computed by the atmospheric water balance assuming no evaporation.

A comparison of the results from the two independent measures shows remarkable agreement and affords a degree of confidence 
Table 2. Comparison of Water Balance Results (P) with Gauge Precipitation Measurements $\left(P_{G}\right)(\mathrm{cm} / 12 \mathrm{hrs})$

\begin{tabular}{cll}
\hline Date/Time & $(P)$ & $P_{G}$ \\
\hline 18/00 MGT & 1.0 & 1.0 \\
18'12 MGT & 1.1 & 1.0 \\
19/00 MGT & 0.5 & 0.5
\end{tabular}

in the quality of the atmospheric water balance data and computational technique.

\subsection{The Mass and Moisture Flow} within the Atmospheric Volume

The atmospheric water balance of the cyclone described in the previous sections furnished a value of the net water yield of the storm system without regard to the distribution within the volume under consideration. The precipitation gauge analysis furnished a description of the areal distribution of the yield over the storm system. We now wish to determine the flow of the mass and the rate of condensation of water within the atmospheric volume. One could divide the volume into sub-volumes of a set geometric shape and perform a water balance computation for smaller and smaller volumes thus defining the residual $P-E$ for each and hence a determination of the distribution of the water flux within the atmospheric volume. One is limited in this approach by the density of observations and accuracy with which one can compute divergence of water vapor flux. Alternately one could divide the volume into physically meaningful sections such that the air on the boundary would be characterized by a conservative property as it goes through the precipitation process and this air then would be followed until it is observed to exit the volume. We chose to use the equivalent potential temperature $\Theta_{e}$ as the conservative property. Let $\Theta_{d}$ be the dry potential temperature, $L$ the latent heat of vaporization, $w$ the mixing ratio, $c_{p}$ the specific heat of air at constant pressure and $T_{s}$ the temperature at saturation. Then $\Theta_{e}=\Theta_{d} \exp \left(\frac{L w^{\prime}}{c_{p} T_{s}}\right)$. This restricts us to the case where any water condensed is assumed to fall out of the volume immediately.

We now have labeled the masses of air either flowing in or out of the volume with a thermodynamic measure conserved through the precipitation or for that matter, evaporation processes. All the mass flows of a particular $\Theta_{e}$ class (class interval of $5^{0} \mathrm{~K}$ ) were grouped 
and tested for mass balance. One may picture the $\Theta_{c}$ class as a "tube" extending over some pressure interval and having varying crosssectional areas on various pressure surfaces. We wish to determine the vertical mass flow at each pressure level within each tube. The tubes may intersect the boundary of the volume at one or more points at each pressure level. At these points the air may be either flowing into or out of the volume. A net horizontal flow of mass was determined for each tube at each pressure surface. These net horizontal mass flows were then accumulated beginning at the lowest level and proceeding to the top. The accumulated net horizontal mass flow at each layer within the $\Theta_{\rho}$ tube is therefore the vertical mass flow at the top of that layer. This technique merely imposes as much geostrophic balance as possible on the determination of the vertical mass flow. Figs. 10-13 show the horizontal and vertical mass flows for all $\Theta_{e}$ tubes for the three time periods. Of particular note is the general decrease of $\Theta_{e}$ values near the ground as the storm proceeds northward and occludes. There is a sizeable quantity of air with $\Theta_{e}=325^{\circ} \mathrm{K}$ or warmer during the first time period (18/00 MGT) while during the last time period (19/00 MGT) the warmest air is in the $315^{\circ}$ range. Further the top of the vertical circulation system progresses downward toward higher pressure from $250 \mathrm{mb}$ to $400 \mathrm{mb}$, over the same period. It should be noted that during the first two time periods the vertical circulation is directed upward in the warmest $\Theta_{e}$ channels and directed downward in the cooler $\Theta_{\rho}$ channels. In the last period the motion is largely upward in all channels but significantly less mass rising in each channel. Evidence of the "tower phenomenon" is apparent early in the storm, particularly for 00 MGT on the 18th. Note that for $\Theta_{e}$ channels $330^{\circ} \mathrm{K}$ and $325^{\circ} \mathrm{K}$ the large inflow of air near the surface has no corresponding outflow at any level until the high troposphere is reached. Areas of $\Theta_{e}$ greater than $320^{\circ} \mathrm{K}$ on intermediate pressure levels, for example the $500 \mathrm{mb}$ level as shown in Fig. 14, are not visible on the synoptic scale. It must be assumed that the vertical transport takes place in towers over the heavy precipitation region of the storm. The intense precipitation region for 0000 MGT, 18 February is delineated by the hatched area on Fig. 14. It is interesting to note that at $500 \mathrm{mb}$ these towers are included in the $315^{\circ} \mathrm{K} \Theta_{e}$ channel which is characterized by a slight downward transport of mass at $500 \mathrm{mb}$ (Figs. 11-12). Let us consider the sounding at point $\mathrm{A}$ on Fig. 14. This sounding is shown on the tephigram of Fig. 15 along with the ascent curves of the $325^{\circ} \Theta_{e}$ and the $330^{\circ} \Theta_{e}$ air. If we assume the sounding of point $A$ to be 


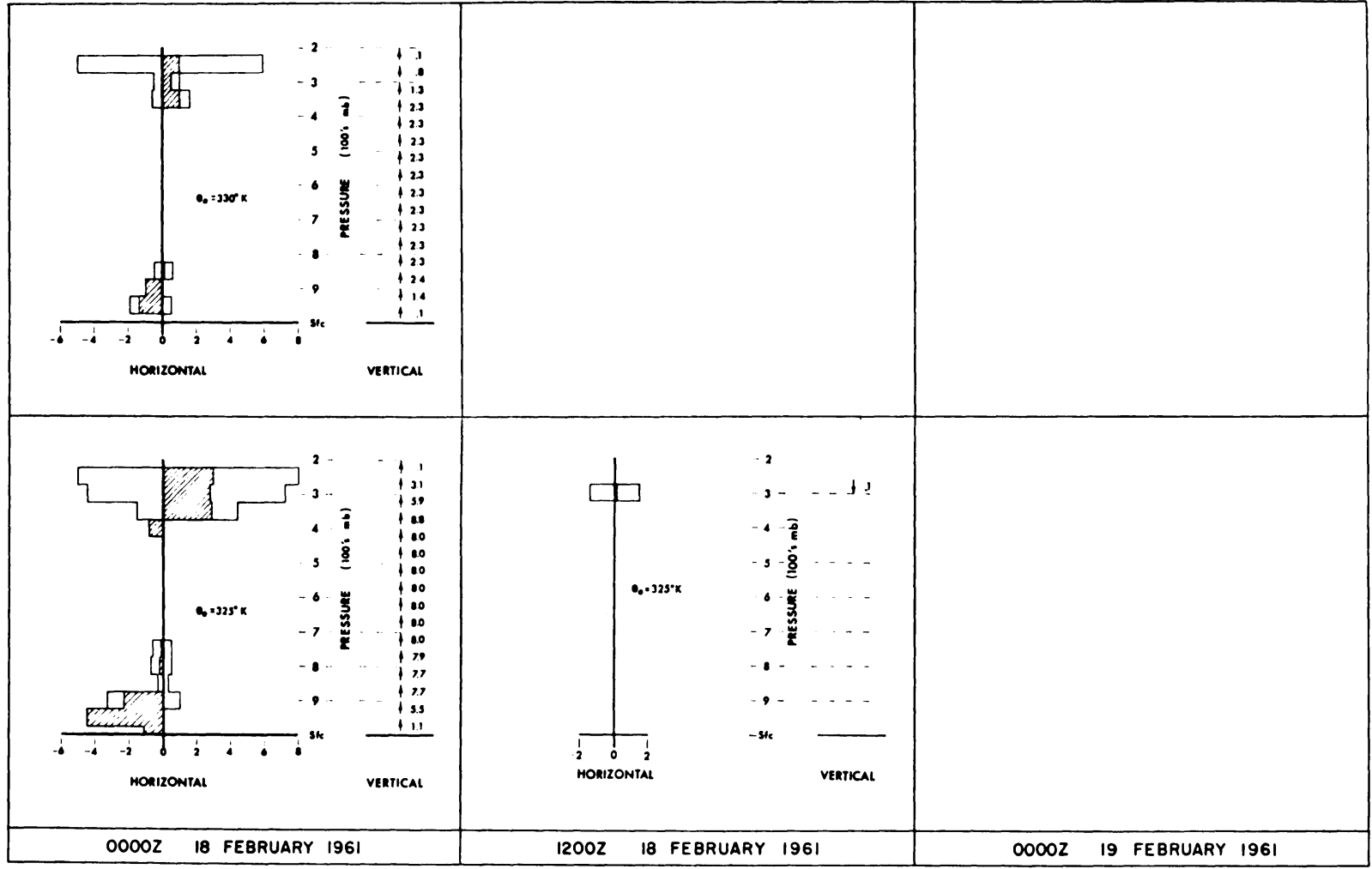

Fig. 10. Horizontal and vertical mass flows within indicated $\Theta_{\rho}$ tubes for each time period. Top row is for $\Theta_{e}=330^{\circ} \mathrm{K}$ and bottom row is for $\Theta_{e}=325^{\circ} \mathrm{K}$. The horizontal mass inflow (negative) and outflow (positive) are noted by the open bars at each pressure layer. The hatched bars are the net horizontal mass flow. The arrows denote the direction of vertical mass flow $\left(\times 10^{12} \mathrm{gm} / \mathrm{sec}\right)$ 


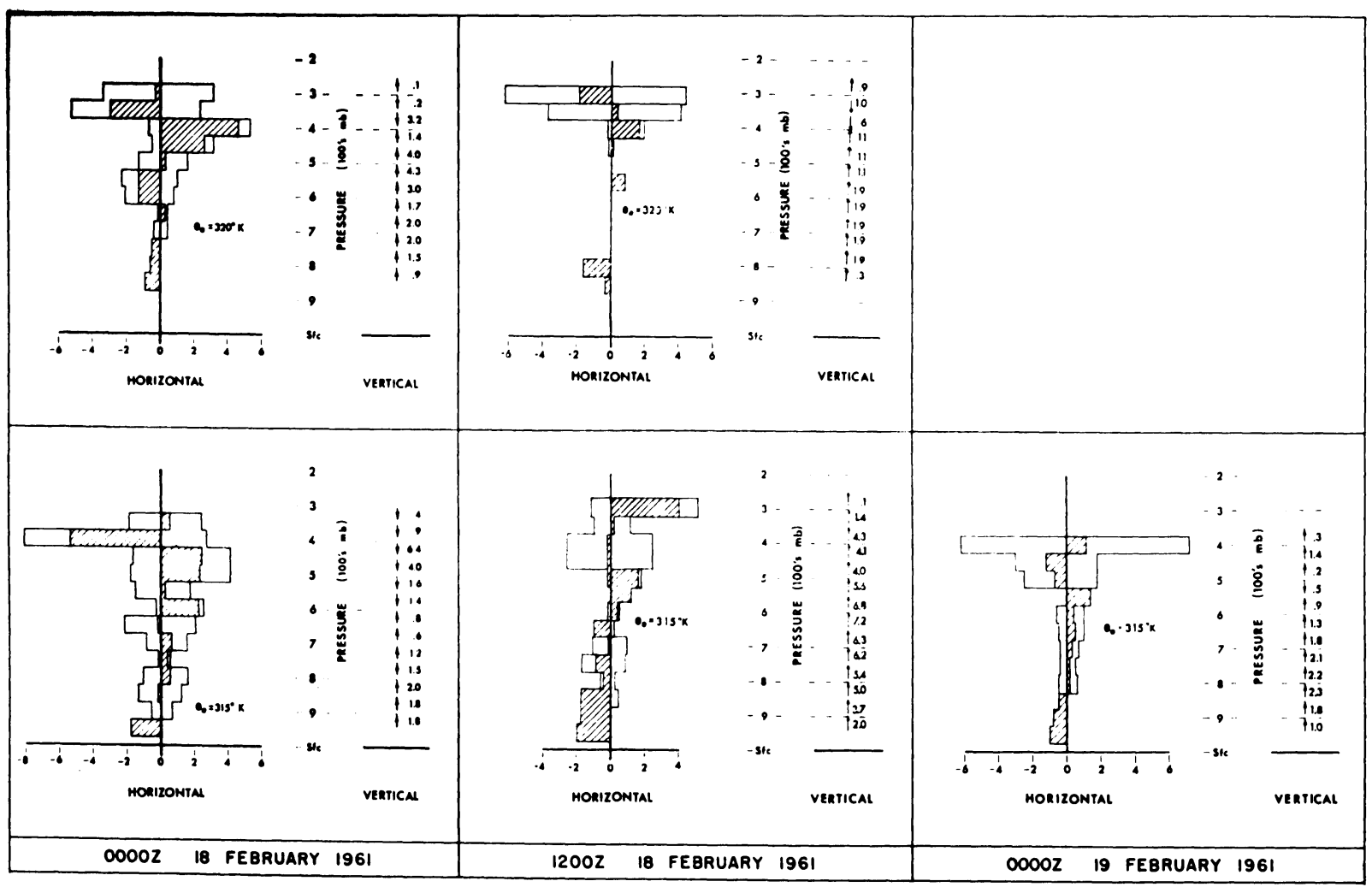

Fig. 11. As Fig. 10: Top row is for $\Theta_{e}=320^{\circ} \mathrm{K}$ and bottom row is for $\Theta_{e}=315^{\circ} \mathrm{K}$ 


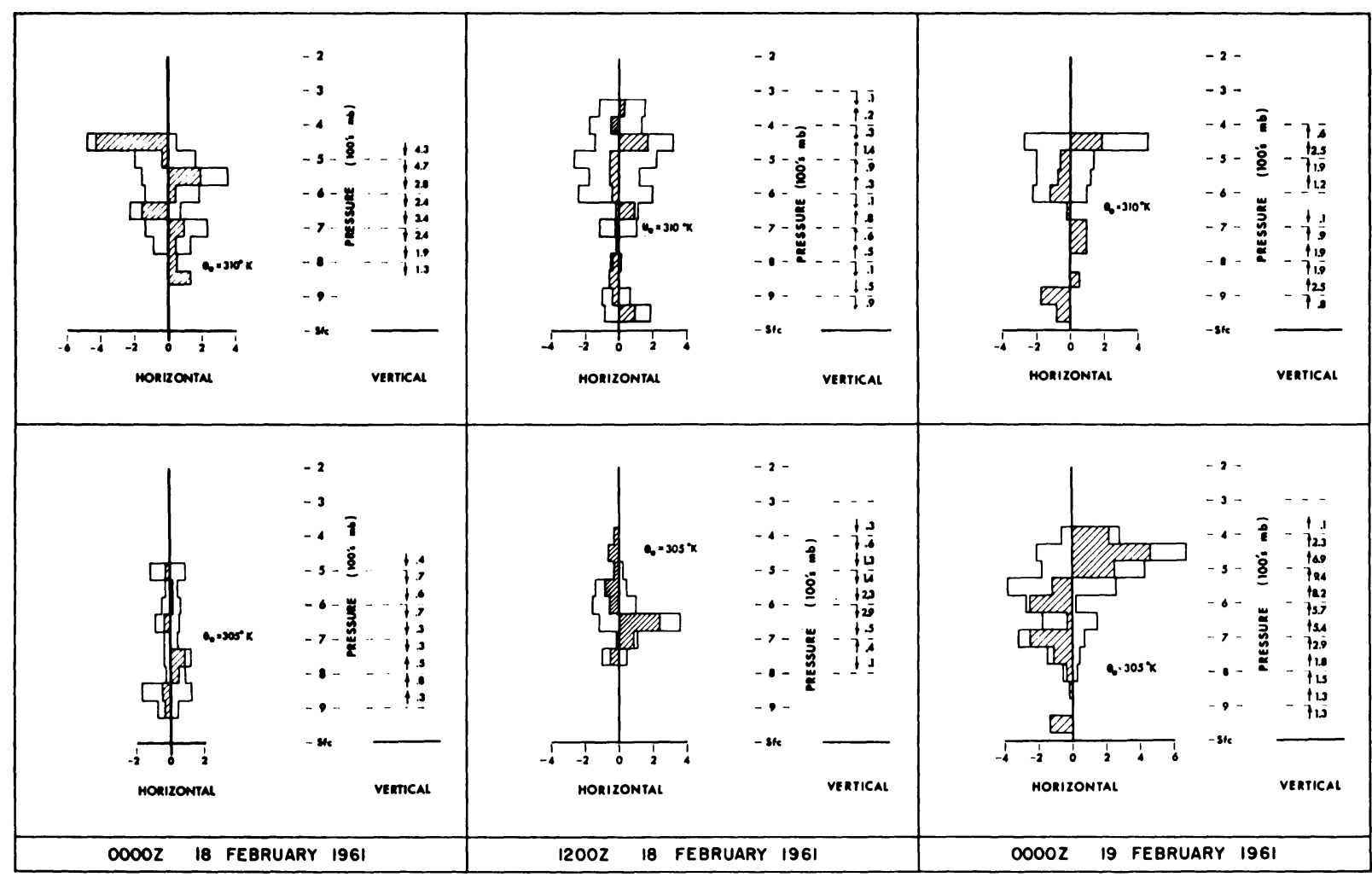

Fig. 12. As Fig. 10: Top row is for $\Theta_{e}=310^{\circ} \mathrm{K}$ and bottom row is for $\Theta_{e}=305^{\circ} \mathrm{K}$ 


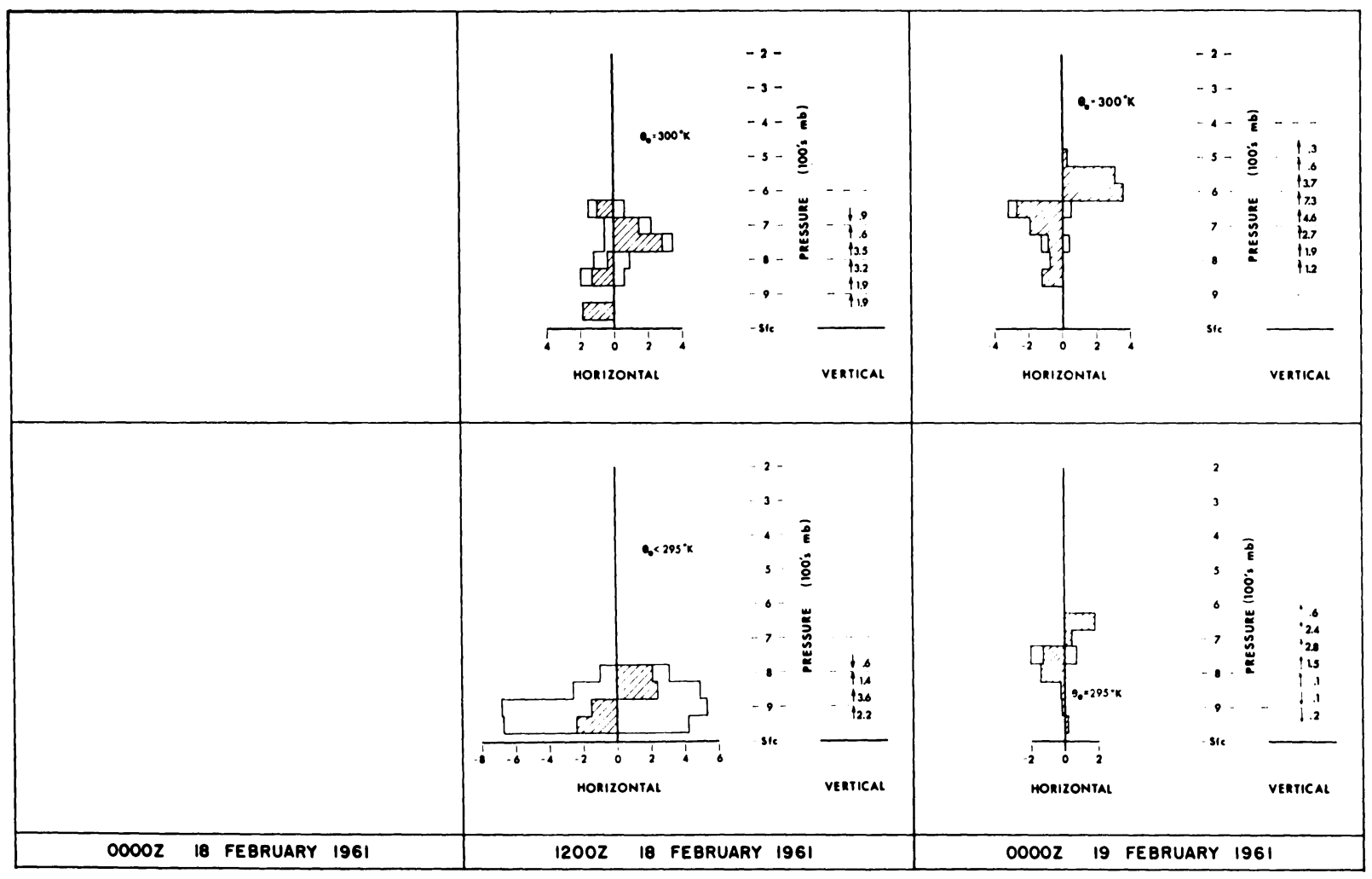

Fig. 13. As Fig. 10: Top row is for $\Theta_{e}=300^{\circ} \mathrm{K}$ and bottom row is for $\Theta_{e}=295^{\circ} \mathrm{K}$ 
representative of the environment in which the towers exist then a high degree of buoyancy exists throughout the troposphere (Fig. 15) and the "hot towers" concept is reasonable. Further, the

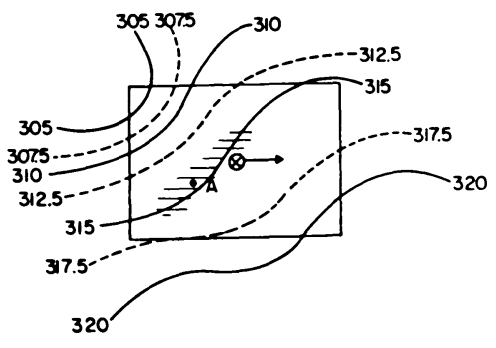

Fig. 14. $\Theta_{e}$ analysis of the $500 \mathrm{mb}$ surface for February 18, 1961, 0000 MGT. Hatched area is the area of heavy precipitation

subsidence at $500 \mathrm{mb}$ in the $315^{\circ} \Theta_{e}$ channel is reflected in the dew point trace shown on Fig. 15.

No significant buoyancy is apparent in the soundings of the last period. The mechanism driving the vertical circulation during this period is the large-scale dynamic effects providing large areas of slowly ascending air covering much of the box.

We may now determine the rate of condensate $C$ forming by following the masses of air rising in the various $\Theta_{e}$ channels and observing

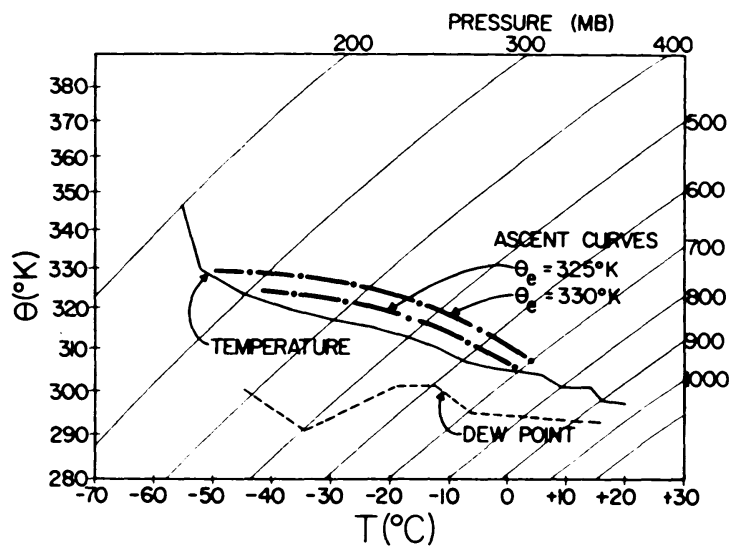

Fig. 15. Sounding at point $A$ on Fig. 14 plotted on a tephigram

the change in saturation specific humidity after the condensation level has been reached. For all time periods the lowest condensation 
level of all rising air masses was in the 850 to $800 \mathrm{mb}$ range. Table 3 shows the total rate of condensate during the three time periods. The units employed are again a unit yield measure so that the values may be compared to the precipitation and water balance results.

Table 3. The Totals of Units of Condensate C, Precipitation Measured Using Water Balance $P$, and Gauge Precipitation $P_{G}$ for the Three Periods (cm/12 hrs)

\begin{tabular}{cccc}
\hline Time & $C$ & $P$ & $P_{G}$ \\
\hline 18'00 MGT & 1.4 & 1.0 & 1.0 \\
18 12 MGT & 0.9 & 1.1 & 1.0 \\
19'00 MGT & 0.6 & 0.5 & 0.5
\end{tabular}

If we define an efficiency of the cloud mass as the ratio of $P$ over $C$ we obtain values of efficiency of $.72,1.22$ and .83 for the three periods, respectively. This efficiency measure of course assumes a steady state of total cloud mass. This assumption is not reasonable as is evidenced by the 1.22 value for the middle period. It is reasonable to expect a diurnal variation in cloud mass particularly for the convective case in the early time periods. The second period covers the time interval of 12 hours centered on 6:00 a. m. local time, a period over which maximum change in cloud cover may be expected. One may hypothesize then that some of the precipitation occurring over that time period was derived from a decrease of total cloud masses that existed at the end of the first period. Satellite and radar coverage of such a storm system would be invaluable in this part of the analysis and we propose this be incorporated into future analyses.

We then asked ourselves the question: Where does this condensation take place? From a cloud physics and weather modification point of view the interest is in the distribution of condensate as a function of cloud temperature. Fig. 16 shows the percentage of the condensation rate as it is related to various temperature classes.

It is interesting to note that as the structure of the storm changes from a statically unstable to a stable system the percentage of condensation taking place at the successive temperature intervals becomes more uniform. This illustrates that in a statically stable system the decrease in water vapor with height is offset by a maximum transport of mass in the middle atmosphere. The buoyant case, on the other hand, has a relatively uniform mass ascent throughout the volume but a larger rate of change of specific humidity follow- 
ing the rising mass at warmer temperatures and therefore a rate of condensation profile rapidly falling off with decreasing temperature.

We observe that at all time periods the mass of condensate is formed at relatively warm temperatures and, if the ice-water process of precipitation formation is dominant, practically all of the cloud mass must be transported vertically to levels where the natural
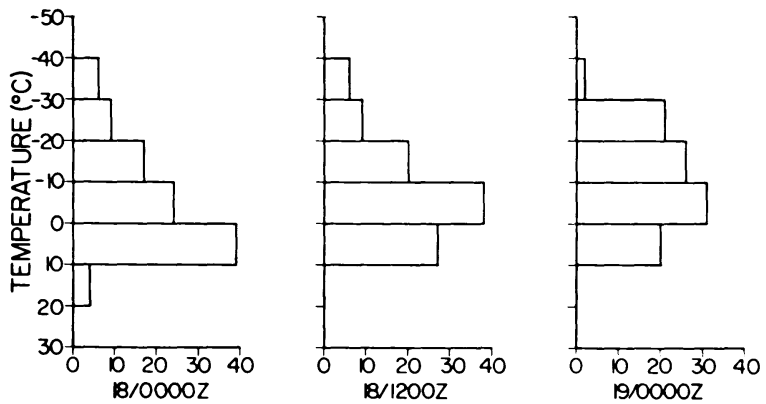

PERCENT TOTAL RATE OF CONDENSATE

Fig. 16. Percent of total rate of condensate for each period classed according to temperature

ice nuclei are active. It appears, therefore, that weather modification techniques could significantly alter the precipitation formation for this storm since the artificial nuclei would become active at relatively warm cloud temperatures as compared to the natural nuclei, and practically all the cloud droplets are passing through this warmer temperature range.

\section{Conclusions and Outlook for Further Research}

The case study presented in this paper provides a step toward the solution of the problems presented in the Introduction. A highly banded precipitation pattern was shown to exist with respect to the moving cyclone. The precipitation rate determined by the atmospheric water balance technique was shown to be accurate. The flow of mass and moisture within the volume was determined using the thermodynamic constraint of constant equivalent potential temperature. The nature of the storm changes from a statically unstable to stable system over the three time periods and a distinct change in the mode of vertical transport of mass and moisture were noted. The rate of condensate as a function of temperature was 
determined and shows that the largest condensation rates occur in the warm temperatures, particularly in the case where the ascent was buoyant.

This case study describes a winter cyclone of average size and intensity. Further examples of the technique should be done for extreme cases. The case of large precipitating systems during the summer are also of interest and should be studied because of the role played by buoyant ascent in these systems. Finally, after a suitable analysis technique has been attained the question of the role of the release of latent heat in the structure and dynamics of cyclone systems can be attacked. Following this, the role of weather modification on cyclone systems may be handled from the point of view of the energy added to the system and its affect on the structure and dynamics of the storm.

\section{Acknowledgement}

This research was sponsored primarily by the Office of Naval Research, Contract No. N 000014-67-A-0299-0003-AN. Partial support was obtained from the Experiment Station, Colorado State University, Fort Collins, Colorado.

The authors wish to adknowledge the help of Mr. LeE Balick who handled the data reduction, and of Mrs. Adrienne Schneider who typed the manuscript.

\section{References}

1. Bradbury, D. L.: Moisture Analysis and Water Budget in Three Different Types of Storms. J. Meteor. 14, 559-565 (1957).

2. Olasconga, M. J.: Some Aspects of Argentine Rainfall. Tellus 2, 312-318 (1950).

3. Palmén, E.: Vertical Circulation and Release of Kinetic Energy during the Development of Hurricane Hazel into an Extratropical Storm. Tellus 10, 1-23 (1958).

4. Palmén, E.: Evaluation of Atmospheric Moisture Transport for Hydrological Purposes. Rept. No. 1, WMO, Internat. Hydrolog. Decade Projects, Geneva, 63 pp., 1967.

5. Palmén, E., and E. O. Holopainen: Divergence, Vertical Velocity and Conversion between Potential and Kinetic Energy in an Extratropical Disturbance. Geophysica 8, 89-113 (1962).

6. Petterssen, S.: Weather Analysis and Forecasting. 2nd ed., New York: McGraw-Hill, 1956.

7. Rasmussen J. L.: Atmospheric Water Balance of the Upper Colorado River Basin. Atmos. Sci. Paper No. 121, Dept. of Atmos. Sci., Colorado State University, Fort Collins, 112 pp., 1968.

8. RieHL, H.: Some Aspects of Hawaiian Rainfall. Bull. Amer. Meteor. Soc. 30, 176-188 (1949). 
9. Riehl, H., and R. Elsberry: Precipitation Episodes in the Upper Colorado River Basin. Geofis. Pura Appl. 57, 213-220 (1964).

10. Riehl, H., and W. Gray: On the Latent Heat Release in a Cyclone Crossing the Rodky Mountains. Tech. Paper No. 35, Dept. of Atmos. Sci., Colorado State University, Fort Collins, 1962.

Authors' address: Dr. J. L. Rasmussen, Mr. R. W. Furman, Dr. H. Riehl, Department of Atmospheric Science, Colorado State University, Fort Collins, CO 80521, U.S. A. 